\title{
Disparities in access to healthcare and the neurosurgeon
}

\author{
Richard Hayward, FRCS (Eng) \\ Pediatric Neurosurgery, Great Ormond Street Hospital for Children, London, United Kingdom
}

I $\mathrm{T}$ is a sad fact of life that every feature distinguishing one human being from another can also be the focus for discriminating against them. The catalog of intolerances is a long one. It opens with major and overlapping entries such as race, economic status, gender, age, education, and mental fragility. Think of these intolerances as malignant weeds whose tendrils become harder to detect the deeper they penetrate the nooks and crannies of everyday life. A particularly egregious example of their influence is on the provision of healthcare, with its predictable effect on mortality and morbidity for those impacted. ${ }^{1}$

The degree to which a society is prepared to tolerate (or deny) disparities in healthcare reflects its fundamental ideology - the moral armature around which the rules and regulations that determine who should and who should not be considered deserving are woven. It is no surprise that this can lead to healthcare systems that range in eligibility for coverage from a government-funded "public" health service, through an array of private and public partnerships, to one in which the public element has withered away, leaving in its wake a grudgingly subsidized safety net of basic amenities.

But all healthcare systems, regardless of their philosophical shading, are expensive, which immediately makes them a matter of politics, and politics of the most sensitive kind. Why else would the US 2003 National Healthcare Disparities Report have been altered prior to publication to present its data in a more positive light? ${ }^{2}$ Not that politicians should take all the blame for colluding with whatever level of discrimination their voters will tolerate. Those dispensing healthcare-some of a society's most respected members-can, consciously or not, be just as susceptible to prejudice and bias toward those whom they serve. ${ }^{3}$

While some disparities in healthcare provision require ideological blinkers of a peculiar opacity to survive, many others can be hard to detect, and none more than those so long embedded in everyday medical life that they are taken for granted. But one way to expose them is through the lens of a particular clinical condition. It is an approach that can be broad-brush, where the target population is large and diffuse, as with pediatrics ${ }^{4}$ or cancer. ${ }^{5}$ Or, by increasing the level of magnification, it can be focused on groups more precisely defined the smaller their numbers: from neurosurgery ${ }^{6,7}$ through craniofacial surgery, ${ }^{8,9}$ until finally, for the purposes of this editorial, down to specific types of craniosynostosis.

This is what the authors of a paper ${ }^{10}$ in this issue of Neurosurgical Focus have done with their examination of variations in the management of premature fusion of a single skull vault suture. This is a condition in the throes of a treatment revolution-the increasing use of endoscopeassisted excision of the affected suture combined with either an internal (springs ${ }^{11,12}$ ) or external (helmet ${ }^{13}$ ) orthosis as a replacement for traditional, more extensive ("open") skull reconstructions. The choice between the two is time sensitive. The endoscopic approach requires the child to be young-younger than 6 months of age, preferably under 3 months-while there is no such limit on the open procedures. Analysis of race, age at presentation, and the operation performed in patients referred to a unit at which both procedures are available therefore has the potential to reveal patterns indicating inequalities in access to specialist care for certain families.

The authors' conclusions are dramatic. Highly significant differences exist between those receiving endoscopeassisted versus open surgery, related to patients' insurance status and race, "with significantly more Black and Hispanic patients treated in the open surgical group." The authors concluded, "Black and Hispanic children and children with Medicaid were more likely to present later and undergo open surgery."

A recent study by Rochlin et al..$^{14}$ also looked at children undergoing either endoscopic or open operations for craniosynostosis (but not confined to single-suture involvement). They concluded that "Racial, socioeconomic, and geographic factors were not significantly associated with treatment type or perioperative surgical outcomes." 
But because they stratified age by whole year rather than by month, the authors were unable to determine how variations in choice of procedure might have affected which side of that vital 3-to 6-month-old cutoff their patients presented. Nevertheless, "Patients who underwent surgical repair at less than 1 year of age were more commonly White (57.8\%), while those who were 1 year of age or older at the time of surgery were more commonly non-White (54.0\%, $P=0.004) . "$

What should the neurosurgical community take from these findings? Neurosurgeons are busy folk absorbed in important, time-consuming, and all-engrossing work. The impetus to examine whether patients presenting for their attention-and more importantly, those not presenting-accurately reflect the community at large can too easily be absorbed into the noise of a hectic practice. But the next time you look out at those anxious faces in the waiting room, why not take a moment to ask if the differences among them might suggest societal forces at work of which you had previously been unaware? It could be a first step toward doing something about it.

https://thejns.org/doi/abs/10.3171/2021.1.FOCUS2124

\section{References}

1. Mackenbach JP, Hu Y, Artnik B, et al. Trends in inequalities in mortality amenable to health care in 17 European countries. Health Aff (Millwood). 2017;36(6):1110-1118.

2. Steinbrook R. Disparities in health care-from politics to policy. $N$ Engl J Med. 2004;350(15):1486-1488.

3. Drewniak D, Krones T, Wild V. Do attitudes and behavior of health care professionals exacerbate health care disparities among immigrant and ethnic minority groups? An integrative literature review. Int J Nurs Stud. 2017;70:89-98.

4. Flores G; Committee on Pediatric Research. Racial and ethnic disparities in the health and health care of children. Pediatrics. 2010;125(4):e979-e1020.

5. Patel M, Lopez AM, Blackstock W, et al. Cancer disparities and health equity: a policy statement from the American Society of Clinical Oncology. J Clin Oncol. 2020;38(29): 3439-3448.
6. Muhlestein WE, Akagi DS, Chotai S, et al. The impact of race on discharge disposition and length of hospitalization after craniotomy for brain tumor. World Neurosurg. 2017; 104:24-38.

7. Missios S, Bekelis K. Access disparities to magnet hospitals for patients undergoing neurosurgical procedures. J Clin Neurosci. 2017;44:47-52.

8. Carmona R, Jones TA, Rosenberg J, et al. Barriers to accessing medical care for Hispanic individuals with craniofacial conditions. Plast Surg Nurs. 2020;40(2):73-80.

9. Zaluzec RM, Rodby K, Bradford PS, et al. Delay in cleft lip and palate surgical repair: an institutional review on cleft health disparities in an urban population. J Craniofac Surg. 2019;30(8):2328-2331.

10. Hoffman C, Valenti AB, Odigie E, et al. Impact of health disparities on treatment for single-suture craniosynostosis in an era of multimodal care. Neurosurg Focus. 2021;50(4):E13.

11. Runyan CM, Gabrick KS, Park JG, et al. Long-term outcomes of spring-assisted surgery for sagittal craniosynostosis. Plast Reconstr Surg. 2020;146(4):833-841.

12. Riordan CP, Zurakowski D, Meier PM, et al. Minimally invasive endoscopic surgery for infantile craniosynostosis: a longitudinal cohort study. J Pediatr. 2020;216:142-149.e2.

13. Fearon JA. Discussion: Long-term outcomes of spring-assisted surgery for sagittal craniosynostosis. Plast Reconstr Surg. 2020;146(4):842-843.

14. Rochlin DH, Sheckter CC, Lorenz HP, et al. Nationwide perioperative analysis of endoscopic versus open surgery for craniosynostosis: equal access, unequal outcomes. J Craniofac Surg. 2021;32(1):149-153.

\section{Disclosures}

The author reports no conflict of interest.

\section{Correspondence}

Richard Hayward: richard.d.hayward@gmail.com.

\section{INCLUDE WHEN CITING}

DOI: 10.3171/2021.1.FOCUS2124. 